\title{
Repellency to Stomoxys calcitrans (Diptera: Muscidae) of Plant Essential Oils Alone or in Combination With Calophyllum inophyllum Nut Oil
}

\author{
TRAN TRUNG HIEU, ${ }^{1}$ SOON-IL KIM ${ }^{2}$ SANG-GUEI LEE, ${ }^{3}$ AND YOUNG-JOON AHN ${ }^{2,4}$
}

\begin{abstract}
J. Med. Entomol. 47(4): 575-580 (2010); DOI: 10.1603/ME09271
ABSTRACT The repellency to female Stomoxys calcitrans (L.) (Diptera: Muscidae) of 21 essential oils (EOs) alone or in combination with Calophyllum inophyllum L. (Clusiaceae) nut oil (tamanu oil) was examined using an exposed human hand bioassay. Results were compared with those of commonly used repellent $N, N$-diethyl-3-methylbenzamide (DEET). In tests with six human male volunteers at a dose of $0.5 \mathrm{mg} / \mathrm{cm}^{2}$, patchouli (protection time [PT], 3.67 h) was the most effective EO but less active than DEET $(4.47 \mathrm{~h})$, as judged by the PT to first bite. Very strong repellency also was produced by clove bud, lovage root, and clove leaf EOs (PT, 3.50-3.25 h), whereas strong repellency was obtained from thyme white $\mathrm{EO}(2.12 \mathrm{~h})$. Thyme red, oregano, and geranium EOs exhibited moderate repellency (PT, $1.24-1.11 \mathrm{~h}$ ). At $0.25 \mathrm{mg} / \mathrm{cm}^{2}$, protection time of clove bud, clove leaf, and lovage root EOs (PT, $\approx 1 \mathrm{~h}$ ) was shorter than that of DEET $(2.17 \mathrm{~h})$. An increase in the protection time was produced by binary mixtures (PT, 2.68-2.04 h) of five EOs (clove bud, clove leaf, thyme white, patchouli, and savory) and tamanu oil $\left(0.25: 2.0 \mathrm{mg} / \mathrm{cm}^{2}\right)$ compared with that of either the constituted essential oil or tamanu oil alone (PT, $0.56 \mathrm{~h}$ ). The protection time of these binary mixtures was comparable with that of DEET. With the exception of savory EO, the other EOs, tamanu oil, and binary mixtures did not induce any adverse effects on the human volunteers at $0.5 \mathrm{mg} / \mathrm{cm}^{2}$. Thus, binary mixtures of essential oils and tamanu oil described merit further study as potential repellents for protection from humans and domestic animals from biting and nuisance caused by S. calcitrans.
\end{abstract}

KEY WORDS Stomoxys calcitrans, natural insect repellent, essential oil, tamanu oil, binary mixtures

The stable fly, Stomoxys calcitrans (L.) (Diptera: Muscidae), is one of the most serious biting and nuisance insect pests of the mostly outdoor environment because of its cosmopolitan occurrence and abundance in livestock barns and stables or sometimes in recreation areas, although it is not important as vector of disease (Newson 1977, Rozendaal 1997). The insect species is known to transmit various livestock diseases (Miller 1995). Both male and female S. calcitrans mostly feed on the legs of domestic animals and on humans in the daytime. Economic importance of $S$. calcitrans has been well described by Newson (1977) and Campbell (1993).

Repellents are one of the most effective tools for protecting humans and domestic animals from bites by nuisance arthropods (Curtis et al. 1990, Rozendaal 1997, Barnard 2000, Isman 2006), as repeated use of conventional insecticides has disrupted natural biological control systems and led to resurgences in insect

${ }^{1}$ Entomology Major, Department of Agricultural Biotechnology, Seoul National University, Seoul 151-921, Republic of Korea.

${ }^{2}$ WCU Biomodulation Major, Department of Agricultural Biotechnology, Seoul National University, Seoul 151-921, Republic of Korea.

${ }^{3}$ National Academy of Agricultural Science, Rural Development Administration, Suwon 441-707, Republic of Korea.

${ }^{4}$ Corresponding author, e-mail: yjahn@snu.ac.kr. populations, has often resulted in the development of resistance (WHO 1992, Rozendaal, 1997), and raises serious human health and environmental concerns (Brown 1978, Levine 1991). The most widely used repellent is $N, N$-diethyl-3-methylbenzamide (DEET), which is still the most effective. This compound has many problems, such as an unpleasant odor, damage to certain plastics and synthetic rubber, and medical issues that include central nervous system depression, urticaria, and contact dermatitis (Knowles 1991, Katz et al. 2008). These problems highlight the need for the development of new improved repellents and strategies for protection from S. calcitrans attack.

Plant essential oils and their constituents have been suggested as alternative sources for arthropod repellent products (Curtis et al. 1990, Quarles 1996, Rozendaal 1997, Das et al. 2003, Ahn et al. 2006, Isman 2006). This approach is appealing, in part, because they are a rich source of bioactive chemicals that often produce only minor adverse effects on nontarget organisms and the environment and often act at multiple and novel target sites. In addition, essential oils are widely available with some being relatively inexpensive compared with plant extracts (Isman 2006). These potential new arthropod repellents can be applied to human and animal skin, clothing, and livestock barns 
Table 1. List of 20 commercial plant essential oils, Z. schinifolium (ZS) fruit steam distillate, and commercial tamanu oil tested for repellency

\begin{tabular}{|c|c|c|}
\hline Common name & Family & Plant species \\
\hline Armoise & Asteraceae & Artemesia vulgaris $\mathrm{L}$. \\
\hline Bergamot & Rutaceae & Citrus bergamia (Risso) Wright and Walder-Arnott \\
\hline Citronella & Poaceae & Cymbopogon nardus (L.) Rendle \\
\hline Clove bud & Myrtaceae & Eugenia caryophyllata Thunberg \\
\hline Clove leaf & Myrtaceae & Eugenia caryophyllata Thunberg \\
\hline Coriander & Apiaceae & Coriandrum sativum $\mathrm{L}$. \\
\hline Eucalyptus & Myrtaceae & Eucalyptus globules Labillardiére \\
\hline Geranium & Geraniaceae & Pelargonium graveolens L'Héritier de Brutelle \\
\hline Lavender & Lamiaceae & Lavandula officinalis Chaix \\
\hline Lovage & Apiaceae & Levisticum officinale $\mathrm{L}$. Koch \\
\hline Marjoram & Lamiaceae & Origanum majorana $\mathrm{L}$ \\
\hline Oregano & Lamiaceae & Origanum vulgare $\mathrm{L}$. \\
\hline Patchouli & Lamiaceae & Pogostemon cablin (Blanco) Bentham \\
\hline Rosemary & Lamiaceae & Rosmarinus officinalis L. \\
\hline Sage, Clary & Lamiaceae & Salvia sclerea $\mathrm{L}$. \\
\hline Sandalwood & Santalaceae & Santalum album $\mathrm{L}$. \\
\hline Savory & Lamiaceae & Satureja monata L. \\
\hline Thyme red & Lamiaceae & Thymus vulgaris $\mathrm{L}$. \\
\hline Thyme white & Lamiaceae & Thymus vulgaris L. \\
\hline Xanthoxylum & Rutaceae & Zanthoxylum armatum de Candolle \\
\hline ZS steam distillate & Rutaceae & Zanthoxylum schinifolium Siebold and Zuccarini \\
\hline Tamanu & Clusiaceae & Calophyllum inophyllum L. \\
\hline
\end{tabular}

and stables in the same manner as the repellents currently used. Thus, much effort has been focused on essential oils and their constituents as potential sources of commercial repellent products largely because certain essential oils and their constituents meet the criteria of minimum risk pesticides (USEPA 1996, 2004). Very little information, however, exists in relation to the repellency of essential oils to S. calcitrans, although their repellency to mosquitoes has been well noted (Curtis et al. 1990, Quarles 1996, Das et al. 2003, Yang et al. 2004).

The current study was aimed at assessing the potential of essential oils for use as commercial repellents. The repellency against female S. calcitrans of 20 commercially available essential oils and a steam distillate and seven selected essential oils alone or in combination with nut oil (called tamanu or dilo oil) from Alexandrian laurel, Calophyllum inophyllum L. (Clusiaceae), was compared with that of DEET.

\section{Materials and Methods}

Materials. Twenty plant essential oils were purchased from Berjé (Bloomfield, NJ) (Table 1). Zanthoxylum armatum fruit essential oil (xanthoxylum or tomar essential oil) and tamanu oil were provided by Seema International (Delhi, India) and Binh Minh (Hochiminh, Vietnam), respectively (Table 1). DEET (97\% purity) was supplied by Sigma-Aldrich (St. Louis, MO). Citrated bovine whole blood was obtained from Innovative Research (Novi, MI). All other chemicals were of reagent grade and available commercially.

Plant and Steam Distillation. The fresh fruits of Zanthoxylum schinifolium (Table 1) were collected in mid-August 2007 at the South Forest Research Center, Korea Forest Research Institute (Jinju, Gyeongnam Province, South Korea). A voucher specimen (ZS-01) was deposited in the Research Institute for Agriculture and Life Sciences, Seoul National University.

Fresh fruit $(130 \mathrm{~g})$ of $\mathrm{Z}$. schinifolium were finely ground and subjected to steam distillation at $100^{\circ} \mathrm{C}$ for $2 \mathrm{~h}$ by using a Clevenger-type apparatus. The volatile oil was dried over anhydrous sodium sulfate and stored in a sealed vial at $4^{\circ} \mathrm{C}$ until use. The yield of the steam distillate was $0.46 \%$ based on dried weight of fruit.

Stable Flies. A colony of S. calcitrans was collected at the animal farm of Seoul National University in August 2007. The collected fly specimens were immediately transferred to cotton mesh cages ( 38 by 38 by $38 \mathrm{~cm}$ ). Adult $S$. calcitrans were maintained on citrated bovine whole blood soaked in cotton pad placed on a dish ( 7 by 7 by $1 \mathrm{~cm}$ ). Larvae were reared in 2 -liter glass beakers containing $200 \mathrm{~g}$ of cow diet (DaeHan Livestock \& Feed, Inchon, South Korea) mixed with $250 \mathrm{ml}$ of distilled water. They were held at $27 \pm 2^{\circ} \mathrm{C}$, $70 \pm 5 \%$ relative humidity $(\mathrm{RH})$, and a photoperiod of 16:8 (L:D) h. Under these conditions, longevity of eggs, larvae, pupae, and adults was $\approx 2.3(2-3), 6.3$ (5-7), 4.6 (3-6), and $14.1(10-16) \mathrm{d}$, respectively.

Bioassay. An exposed human hand bioassay with six human volunteers was used to evaluate the repellency of 21 essential oils to female $S$. calcitrans (3-6 d old). Every bioassay was conducted within the time zone of 1300-1700 hours. Groups of 15 female S. calcitrans were transferred into a crystal grade polystyrene Incu tissue box ( 7 by 7 by $19.6 \mathrm{~cm}$ ) (SPL Lifesciences, Pocheon, Gyeonggi Province, South Korea) because the biting density plays an important role (Schreck 1995, Rozendaal 1997). Two quantities (12.5 and 6.25 $\mathrm{mg}$ ) of the test materials, each in $100 \mu \mathrm{l}$ of ethanol, were directly applied evenly to the exposed skin of the back of the hand through a rectangle $(5 \mathrm{by} 5 \mathrm{~cm})$ made on back part of a rubber glove, which are equivalent to 0.5 and $0.25 \mathrm{mg} / \mathrm{cm}^{2}$, respectively. Controls received $100 \mu \mathrm{l}$ of ethanol. After drying in the air for 2 
min, the treated hands of each volunteer were exposed to female S. calcitrans for $5 \mathrm{~min}, 10 \mathrm{~min}$ after test material application, and then every 20 min until the test volunteer received a S. calcitrans bite at the same conditions used for colony maintenance. DEET served as a positive control for comparison in repellency tests. Each assay was replicated three times. If a test material caused $>0.50 \mathrm{~h}$ of protection time at 0.5 $\mathrm{mg} / \mathrm{cm}^{2}$, further bioassays were done at $0.25 \mathrm{mg} / \mathrm{cm}^{2}$.

In a separate experiment with six volunteers, the repellency of the seven selected essential oils $(0.25$ $\left.\mathrm{mg} / \mathrm{cm}^{2}\right)$ alone or in combination with tamanu oil $(2.0$ $\left.\mathrm{mg} / \mathrm{cm}^{2}\right)$ and DEET was examined as stated above. Tamanu oil was selected for synergy tests because $C$. inophyllum mature fruit is burned for mosquito repellent (Friday and Okano 2006). In a preliminary experiment, the appropriate quantity of tamanu oil was found to be $2 \mathrm{mg} / \mathrm{cm}^{2}$. Each assay was replicated three times.

Dermatological Test. An EPA toxicity classification (USEPA 2010) was used to determine whether treatment with the test essential oils, tamanu oil, and binary mixtures induce dermal irritation. The test materials were applied evenly to the skin below the elbow and the knees of six human male volunteers $(22-40 \mathrm{yr}$ old $)$. The observations were made by S.G.L.

Data Analysis. Protection time (PT) was recorded according to the method of Gillij et al. (2008). PT was the time elapsed between the test material application and the observation period immediately preceding that in which a confirmed bite was obtained. The Bonferroni multiple-comparison method was used to test for significant differences among the test materials (SAS Institute 2004). Means \pm SE of untransformed data are reported. The repellency was classified as follows: very strong, PT >3.0; strong, PT 2.1-3.0 h; moderate, PT 1.1-2.0 h; weak, PT $0.5-1.0 \mathrm{~h}$; and very weak repellency, $\mathrm{PT}<0.5 \mathrm{~h}$.

\section{Results}

Repellency of Essential Oils Tested. The repellency of 21 essential oils and DEET against female S. calcitrans was evaluated by the exposed human hand bioassay (Table 2). Based on the protection time, patchouli (PT, 3.67 h) was the most effective essential oil, followed by clove bud, lovage root, and clove leaf essential oils $(3.50-3.25 \mathrm{~h})$. Thyme white essential oil exhibited strong repellency (PT, $2.12 \mathrm{~h}$ ). Moderate repellency was produced by thyme red, oregano, and geranium essential oils (PT, 1.24-1.11 h). Weak to very weak repellency was observed with the other 12 essential oils (PT, 0.62-0.12). Overall these essential oils were less effective than DEET (PT, $4.47 \mathrm{~h})$. S. calcitrans bites occurred within the 3 min in the ethanol treated controls (average biting pressure, $14 \pm 0.1$ females per person per 5 min).

Because of their potent repellency above, 11 selected essential oils at $0.25 \mathrm{mg} / \mathrm{cm}^{2}$ were likewise compared (Table 3). Effective protection time of clove bud, clove leaf, lovage root, and savory essential oils was $1.20,1.17,1.15$, and $1.00 \mathrm{~h}$, respectively,
Table 2. Repellency of 20 commercial essential oils, Z. schinifolium (ZS) fruit steam distillate, and DEET against female $S$. calcitrans by using the skin bioassay, exposed at $0.5 \mathrm{mg} / \mathrm{cm}^{2}$

\begin{tabular}{ll}
\hline \hline \multicolumn{1}{c}{ Essential oil } & $\begin{array}{c}\text { Protection time } \\
(\text { mean } \pm \mathrm{SE}, \mathrm{h})^{b}\end{array}$ \\
\hline Patchouli & $3.67 \pm 0.096 \mathrm{~b}$ \\
Clove bud & $3.50 \pm 0.048 \mathrm{~b}$ \\
Lovage root & $3.36 \pm 0.074 \mathrm{~b}$ \\
Clove leaf & $3.25 \pm 0.048 \mathrm{~b}$ \\
Thyme white & $2.12 \pm 0.026 \mathrm{c}$ \\
Thyme red & $1.24 \pm 0.039 \mathrm{~d}$ \\
Oregano & $1.15 \pm 0.035 \mathrm{~d}$ \\
Geranium & $1.11 \pm 0.075 \mathrm{~d}$ \\
Bergamot & $0.62 \pm 0.024 \mathrm{e}$ \\
Xanthoxylum & $0.58 \pm 0.029 \mathrm{e}$ \\
Sage, Clary & $0.49 \pm 0.029 \mathrm{ef}$ \\
Lavender & $0.48 \pm 0.015 \mathrm{efg}$ \\
ZS steam distillate & $0.36 \pm 0.015 \mathrm{fgh}$ \\
Armois & $0.30 \pm 0.035 \mathrm{ghi}$ \\
Sandal wood & $0.27 \pm 0.059 \mathrm{hi}$ \\
Citronella & $0.26 \pm 0.034 \mathrm{hij}$ \\
Rosemary & $0.21 \pm 0.024 \mathrm{hijk}$ \\
Coriander & $0.20 \pm 0.015 \mathrm{ijk}$ \\
Eucalyptus & $0.13 \pm 0.019 \mathrm{jk}$ \\
Marjoram & $0.12 \pm 0.024 \mathrm{k}$ \\
Savory & \\
DEET & \\
\hline
\end{tabular}

${ }^{a}$ Time to first bite of the stable fly.

${ }^{b}$ Means within a column followed by the same letter are not significantly different $(P=0.05$; Bonferroni method).

${ }^{c}$ Data were not available because of skin irritation of the essential oil at $0.5 \mathrm{mg} / \mathrm{cm}^{2}$.

whereas that of DEET was $2.17 \mathrm{~h}$. The other seven essential oils exhibited weak to very weak repellency (PT, $0.63-0.23 \mathrm{~h}$ ) as judged by the protection time.

Repellency of Binary Mixtures. The repellency to female S. calcitrans of binary mixtures of the seven selective essential oils $\left(0.25 \mathrm{mg} / \mathrm{cm}^{2}\right)$ and tamanu oil $\left(2 \mathrm{mg} / \mathrm{cm}^{2}\right)$ was likewise compared with that of DEET $\left(0.25 \mathrm{mg} / \mathrm{cm}^{2}\right)$ (Table 4$)$. The exposed human hand bioassays revealed that tamanu oil synergized the repellency of each essential oil tested. For example, tamanu oil was found to synergize the repellency of lovage root essential oil in that the binary mixtures of

Table 3. Repellency of 11 selected essential oils and DEET against female $S$. calcitrans by using the skin bioassay, exposed at $0.25 \mathrm{mg} / \mathrm{cm}^{2}$

\begin{tabular}{lc}
\hline \hline Essential oil & $\begin{array}{c}\text { Protection time }^{a} \\
(\text { mean } \pm \mathrm{SE}, \mathrm{h})^{b}\end{array}$ \\
\hline Clove bud & $1.20 \pm 0.051 \mathrm{~b}$ \\
Clove leaf & $1.17 \pm 0.070 \mathrm{~b}$ \\
Lovage root & $1.15 \pm 0.044 \mathrm{~b}$ \\
Savory & $1.00 \pm 0.069 \mathrm{~b}$ \\
Patchouli & $0.63 \pm 0.024 \mathrm{c}$ \\
Thyme white & $0.58 \pm 0.042 \mathrm{c}$ \\
Geranium & $0.46 \pm 0.024 \mathrm{~cd}$ \\
Oregano & $0.40 \pm 0.035 \mathrm{~d}$ \\
Thyme red & $0.38 \pm 0.024 \mathrm{de}$ \\
Xanthoxylum & $0.25 \pm 0.029 \mathrm{ef}$ \\
Bergamot & $0.23 \pm 0.015 \mathrm{f}$ \\
DEET & $2.17 \pm 0.029 \mathrm{a}$ \\
\hline
\end{tabular}

${ }^{a}$ Time to first bite of the stable fly.

${ }^{b}$ Means within a column followed by the same letter are not significantly different ( $P=0.05$; Bonferroni method). 
Table 4. Repellency of seven selected EOs alone or in combination with tamanu oil and DEET against female $S$. calcitrans by using the skin bioassay

\begin{tabular}{cc}
\hline \hline Treatment $\left(\mathrm{mg} / \mathrm{cm}^{2}\right)$ & $\begin{array}{c}\text { Protection time } \\
(\text { mean } \pm \mathrm{SE}, \mathrm{h})^{b}\end{array}$ \\
\hline Lovage root EO only, 0.25 & $1.13 \pm 0.029 \mathrm{de}$ \\
$\quad+$ tamanu oil, 2.0 & $2.68 \pm 0.087 \mathrm{a}$ \\
Patchouli EO only, 0.25 & $0.69 \pm 0.034 \mathrm{f}$ \\
$\quad+$ tamanu oil, 2.0 & $2.30 \pm 0.072 \mathrm{~b}$ \\
Clove bud EO only, 0.25 & $1.35 \pm 0.035 \mathrm{~d}$ \\
$\quad+$ tamanu oil, 2.0 & $2.27 \pm 0.035 \mathrm{~b}$ \\
Thyme white EO only, 0.25 & $0.64 \pm 0.063 \mathrm{f}$ \\
$\quad+$ tamanu oil, 2.0 & $2.22 \pm 0.040 \mathrm{~b}$ \\
Clove leaf EO only, 0.25 & $1.06 \pm 0.040 \mathrm{e}$ \\
$\quad+$ tamanu oil, 2.0 & $2.21 \pm 0.024 \mathrm{~b}$ \\
Savory EO only, 0.25 & $0.96 \pm 0.024 \mathrm{e}$ \\
$\quad+$ tamanu oil, 2.0 & $2.04 \pm 0.029 \mathrm{~b}$ \\
Geranium EO only, 0.25 & $0.41 \pm 0.039 \mathrm{~g}$ \\
$\quad+$ tamanu oil, 2.0 & $1.67 \pm 0.053 \mathrm{c}$ \\
Tamanu oil only, 2.0 & $0.56 \pm 0.034 \mathrm{fg}$ \\
DEET, 0.25 & $2.20 \pm 0.067 \mathrm{~b}$ \\
\hline
\end{tabular}

\footnotetext{
${ }^{a}$ Time to first bite of the stable fly.

${ }^{b}$ Means within a column followed by the same letter are not significantly different ( $P=0.05$; Bonferroni method).
}

the essential oil with tamanu oil (PT, $2.68 \mathrm{~h}$ ) resulted in significantly greater repellency than either lovage root essential oil $(1.13 \mathrm{~h})$, tamanu oil $(0.56 \mathrm{~h})$, or DEET alone $(2.20 \mathrm{~h})$ based on the protection time. The protection time of binary mixtures of each essential oil (clove bud, clove leaf, patchouli, savory, and thyme white) and tamanu oil (PT, 2.30-2.04) was almost identical to that of DEET. Effective protection time of binary mixture of geranium essential oil and tamanu oil was $1.67 \mathrm{~h}$.

Allergic Reaction. The test essential oils, tamanu oil, and their binary mixtures did not induce any allergic reactions at $0.5 \mathrm{mg} / \mathrm{cm}^{2}$ with the exception of savory essential oil. The essential oil induced slightly dermal irritation (EPA toxicity category IV) to one of six volunteers at $0.5 \mathrm{mg} / \mathrm{cm}^{2}$ but no dermal irritation was observed at $0.25 \mathrm{mg} / \mathrm{cm}^{2}$.

\section{Discussion}

Essential oils consist of highly complex mixtures of the hydrocarbons, such as terpenes (monoterpenes, sesquiterpenes, and diterpenes), and the oxygenated compounds, such as esters, aldehydes, ketones, alcohols, phenols, and oxides (Sellar 2001, Lawless 2002). They jointly or independently contribute to behavioral efficacy, such as repellency and feeding deterrence, and physiological efficacy, such as acute toxicity and developmental disruption, against various arthropod species (Isman 2006). Many plant extracts and essential oils manifest repellency against various arthropod species (Curtis et al. 1990, Rozendaal 1997, Yang et al. 2004, Ahn et al. 2006, Isman 2006). Recently, Mehlhorn et al. (2005) reported that seed extract from monk's pepper, Vitex agnus castus L. (Verbenaceae), was effective as a repellent against eight blood-sucking arthropods, including S. calcitrans. Little work has been done to consider the potential of essential oils to manage S. calcitrans. In the current study with female
S. calcitrans, repellency varied according to essential oil and exposure dose tested. As judged by the protection time, potent activity was observed with clove bud, clove leaf, geranium, lovage root, oregano, patchouli, thyme red, and thyme white essential oils at 0.5 $\mathrm{mg} / \mathrm{cm}^{2}$ without adverse effects on six human volunteers. This is the first report of the repellency of the essential oils to S. calcitrans and these essential oils may hold promise as novel and effective repellent products. Several products based on essential oils, such as citronella, fennel, geranium, lavender, and rosemary, have been commercialized (Curtis et al. 1990, Brown and Hebert 1997).

The effectiveness and duration of inherent repellency of essential oils or chemicals depend on the type of active ingredients, the frequency, formulation of application, test conditions such as tested arthropod species and involved volunteers, loss due to removal by perspiration and abrasion, and the numerical density of arthropods (Schreck 1995, Rozendaal 1997). The effective protective lasting time of many commercial products or formulations based on essential oils is typically $<1 \mathrm{~h}$ under field conditions (Rozendaal 1997, Barnard 2000, Fradin and Day 2002, Kim et al. 2004, Isman 2006). For example, MossZero aerosol containing $5 \%$ fennel oil, MossZero cream containing $8 \%$ fennel oil and MeiMei cream containing citronella and geranium oils produced 84,70 , and $57 \%$ repellency, respectively at $90 \mathrm{~min}$ after exposure, whereas Repellan S aerosol containing 19\% DEET gave $89 \%$ repellency at $210 \mathrm{~min}$ (Kim et al. 2004). In the current study with six human volunteers, clove bud, clove leaf, lovage root, and patchouli essential oils gave protection from female $S$. calcitrans bites for $\approx 3-4 \mathrm{~h}$ at $0.5 \mathrm{mg} / \mathrm{cm}^{2}$, although the protection time of the essential oils was slightly shorter than that of DEET. Geranium, oregano, thyme red, and thyme white essential oils provided protection from fly bites for $\approx 1 \mathrm{~h}$ at the same dose. This different protection time may be attributed to the difference in the quantitative loss due to the volatility of chemical constituents of the essential oils tested. It has been reported that the protection time of $V$. a. castus seed extract against $S$. calcitrans lasted at $\approx 3 \mathrm{~h}$ (Mehlhorn et al. $2005)$. The ability of a chemical vapor to repel is related to its boiling point with boiling points between 230 and $260^{\circ} \mathrm{C}$ at atmospheric pressure being the most desirable range for an effective repellent (Brown and Hebert 1997). Essential oil constituents are somewhat volatile (Lawless 2002, Isman 2006), whereas DEET is almost nonvolatile $\left(111^{\circ} \mathrm{C} / 1 \mathrm{mmHg}\right)$ (Knowles 1991).

Various controlled-release formulations have been developed to increase repellency effectiveness and duration (Khan et al. 1975, Gupta and Rutledge 1989, Sharma and Ansari 1994, Dua et al. 1996). Lantana camara L. flower extract in coconut oil provides $94.5 \%$ protection from Aedes albopictus (Skuse) and Aedes aegypti (L.) without adverse effects on the human volunteers for a 3-mo period after the application (Dua et al. 1996). Khan et al. (1975) reported that the mixtures of DEET and vanillin (1:1, 1:2, and 1:3) against mosquitoes increased from 5 to $12-14 \mathrm{~h}$ com- 
pared with DEET application alone in the protective lasting time. In the current study, the increase in the protection time was produced by binary mixtures of seven test essential oils and tamanu oil (1:8 by weight) against female $S$. calcitrans compared with the constituted oil and DEET application alone. The improved effectiveness might be attributed to the lower evaporation rate and the better skin persistence of the essential oil by the addition of tamanu oil.

Results of the current study indicate that the bioactive essential oil-derived products, including binary mixtures of each essential oil and with tamanu oil tested, could be useful as repellents for protecting humans and domestic animals from bites and nuisance caused by S. calcitrans, provided that a carrier giving a slow release of active compounds can be selected or developed and sealing of the structure of barns or stables is maximized. For the practical use of the essential oil-derived products as novel S. calcitrans repellents to proceed, further research is needed to establish their human safety. However, essential oils are used as fragrances and flavoring agents for foods, beverages and cosmetics (Sellar 2001, Lawless 2002). In addition, their repellent modes of action need to be established and formulations for improving repellency potency and stability, thereby reducing costs, need to be developed.

\section{Acknowledgments}

This work was supported by the Rural Development Administration (BioGreen 21 Program [PJ007109]) and the Ministry of Education, Science and Technology of Korean Government (World Class University Program (R31-10056) (to Y.-J.A.).

\section{References Cited}

Ahn, Y. J., S. I. Kim, H. K. Kim, and J. H. Tak. 2006. Naturally occurring house dust mites control agents: development and commercialization, pp. 269-289. In M. Rai and M. C. Carpinella [eds.], Naturally occurring bioactive compounds. Elsevier, London, United Kingdom.

Barnard, D. R. 2000. Repellents and toxicants for personal protection. World Health Organization, Department of Control, Prevention and Eradication, Programme on Communicable Diseases, WHO Pesticide Evaluation Scheme (WHOPES), WHO/CDS/WHOPES/GCDPP/ 2000.5. World Health Organization, Geneva, Switzerland.

Brown, A.W.A. 1978. Ecology of pesticides. Wiley, New York.

Brown, M., and A. A. Hebert. 1997. Insect repellents: an overview. J. Am. Acad. Dermatol. 36: 243-249.

Campbell, J. B. 1993. The economics of the fly problem, pp. 34-39. In G. D. Thomas and S. R. Skoda [eds.], Rural flies in the urban environment. North Central Regional Research Publication No. 335, University of Nebraska, Lincoln, NE.

Curtis, C. F., J. D. Lives, L. U. Baolib, and A. Renz. 1990. Natural and synthetic repellents, pp. 75-92. In C. F. Curtis [ed.], Appropriate technology in vector control. CRC, Boca Raton, FL.

Das, N. G., I. Baruah, P. K. Talukdar, and S. C. Das. 2003. Evaluation of botanicals as repellents against mosquitoes. J. Vector Borne Dis. 40: 49-53.
Dua, V. K., N. C. Gupta, A. C. Pandey, and V. P. Sharma. 1996. Repellency of Lantana camara (Verbenaceae) flowers against Aedes mosquitoes. J. Am. Mosq. Control Assoc. 12: 406-408.

Fradin, M. S., and J. F. Day. 2002. Comparative efficacy of insect repellents against mosquito bites. New Engl. J. Med. 347: 13-18.

Friday, J. B., and D. Okano. 2006. Calophyllum inophyllum (kamani). Species profiles for Pacific Island agroforestry. (www.traditionaltree.org).

Gillij, Y. G., R. M. Gleiser, and J. A. Zygadlo. 2008. Mosquito repellent activity of essential oils of aromatic plants growing in Argentina. Bioresour. Technol. 99: 2507-2515.

Gupta, R. K., and L. C. Rutledge. 1989. Laboratory evaluation of controlled release repellent formulations on human volunteers under three climatic regimens. J. Am. Mosq. Control Assoc. 5: 52-55.

Isman, M. B. 2006. Botanical insecticides, deterrents, and repellents in modern agriculture and increasingly regulated world. Annu. Rev. Entomol. 51: 45-66.

Katz, T. M., J. H. Miller, and A. A. Hebert. 2008. Insect repellents: historical perspectives and new developments. J. Am. Acad. Dermatol. 58: 865-871.

Khan, A. A., H. I. Maibach, and D. L. Skidmore. 1975. Addition of vanillin to mosquito repellents to increase protection time. Mosq. News 35: 223-225.

Kim, S. I., K. S. Chang, Y. C. Yang, B. S. Kim, and Y. J. Ahn. 2004. Repellency of fennel oil-containing aerosol and cream products to mosquitoes under laboratory and field conditions. Pest Manag. Sci. 60: 1125-1130.

Knowles, C. O. 1991. Miscellaneous pesticides, pp. 14711526. In J. B. Hayes, Jr., and E. R. Laws, Jr. [eds.], Handbook of pesticide toxicology. Academic, San Diego, CA.

Lawless, J. 2002. The encyclopedia of essential oils. Thorsons, London, United Kingdom.

Levine, R. 1991. Recognized and possible effects of pesticides in humans, pp. 275-360. In J. B. Hayes, Jr., and E. R. Laws, Jr. [eds.], Handbook of pesticide toxicology. Academic, San Diego, CA.

Mehlhorn, H., G. Schmahl, and J. Schmidt. 2005. Extract of the seeds of the plant Vitex agnus castus proven to be highly efficacious as a repellent against ticks, fleas, mosquitoes and biting flies. Parasitol. Res. 95: 363-365.

Miller, R. W. 1995. The stable fly as a pest of dairy cattle, pp. 12-20. In G. D. Thomas and S. R. Skoda [eds.], The stable fly: a pest of humans and domestic animals. Agricultural Research Division, Institute of Agriculture and Natural Resources, University of Nebraska (MP64), Lincoln, NE.

Newson, H. D. 1977. Arthropod problems in recreation areas. Annu. Rev. Entomol. 22: 333-353.

Quarles, W. 1996. Botanical mosquito repellents. Common Sense Pest Control 12: 12-19.

Rozendaal, J. A. 1997. Vector control: methods for use by individuals and communities. World Health Organization, Geneva, Switzerland.

SAS Institute. 2004. SAS OnlineDoc, version 8.01. SAS Institute, Cary, NC.

Schreck, C. 1995. Protection from blood-feeding arthropods, pp. 813-830. In P. S. Auerbach [ed.], Wilderness medicine: management of wilderness and environmental emergencies. Mosby, St. Louis, MO.

Sellar, W. 2001. The directory of essential oils. The C. W. Daniel Company Limited, Saffron Walden, Essex, United Kingdom.

Sharma, V. P., and M. A. Ansari. 1994. Personal protection from mosquitoes (Diptera: Culicidae) by burning neem oil in kerosene. J. Med. Entomol. 31: 505-507. 
[USEPA] U.S. Environmental Protection Agency. 1996. Exemption of certain pesticide substances from federal insecticide, fungicide, and rodenticide act requirements. U.S. Environmental Protection Agency, Final Rule, 40 CFR 152.25(g), May 6.

[USEPA] U.S. Environmental Protection Agency. 2004. Biopesticides-25b. Minimum risk pesticides. (http://www.epa. gov/oppbppd1/biopesticides/regtools/25b_list.htm).

[USEPA] U.S. Environmental Protection Agency. 2010. Toxicity category. U.S. Environmental Protection Agency, 40 CFR 156.62, February 26.
[WHO] World Health Organization. 1992. Vector resistance to pesticides, pp. 1-62. Fifteenth Report of the WHO Expert Committee on Vector Biology and Control, Technical Report Ser. 818. World Health Organization, Geneva, Switzerland.

Yang, Y. C., E. H. Lee, H. S. Lee, D. K. Lee, and Y. J. Ahn. 2004. Repellecy of aromatic medicinal plant extracts against Aedes aegypti (Diptera: Culicidae). J. Am. Mosq. Control Assoc. 20: 146-149.

Received 11 November 2009; accepted 13 March 2010. 